\title{
What about Online Information in Web 2.0 Era? A Research Proposal about Critical Thinking Strategies Mobilized by Learners at the Gate of University
}

\author{
Florent Michelot \\ Université de Montréal, Québec
}

\begin{abstract}
This research project aims to obtain an overview on learners critical thinking strategies throughout a connectivist pedagogical scenario in order to evaluate learners' Metaliteracy (i.e. information literacy), specifically with regard to information critical thinking strategies and evaluation skills on social media platforms. To this end, our goal is to develop a mixed methodology, framed by a social cognitive learning epistemology in the context of which critical thinking is interpreted as a cognitive self-regulation strategy. Eventually, the study could provide the educational environment some tools to support learners, especially when it comes to plagiarism and sources quality problems.
\end{abstract}

\section{Introduction}

Since the development of Information communication technologies (ICTs) and its astonishingly rapid improvements, "infobesity" [1] tends to become a challenge to cognitive management. In a few decades, the growth of information resulted in the dismantling of the traditional model, until an almost total situation of "cognitive market" deregulation [2]. Political, social or economic news: the last years are full of news where true and false are intermingled, including among reputed media. Rumor is not a recent phenomenon: sociology has amply described it. But ICTs seem to give it a new impetus. If data are more accessible, availability doesn't come without problems: managing abundance of information becomes a challenge.

Indeed, during the last politics events, dissemination of false or misleading information on social media have been revealed to the public: popularized under the name of "fake news," these phenomena revealed new and emerging practices that should be studied, particularly among students.

Considering this context, many authors like Siemens [3] or Downes [4] have been proposing a connectivist learning theory for over 10 years. It postulates in particular that "evaluating information prior to engaging with that information is a metaskill that [should be] applied before learning begins." This assumption is close to what new Information literacy frameworks, as Metaliteracy, suggests being at the heart of the ability to "know how to learn because they know how knowledge is organized, how to find information and how to use information in such a way that others can learn from them" [5].

We believe that there is therefore an issue linked to critical thinking, understood as the "disciplined process of actively and skillfully conceptualizing, applying, analyzing, synthesizing, and/or evaluating information gathered from, or generated by, observation, experience, reflection, reasoning, or communication, as a guide to belief and action" [6].

To answer that, social cognitive theory offers a framework to interpret regulation mechanisms, both in terms of social regulation and self-regulation strategies as a product of metacognition. Indeed, we retain the proposal that metacognition may have a direct impact on learners' critical thinking strategies.

After introducing some problematic elements, we will present our objectives and sa part of our conceptual framework that will be mobilized all along the steps of this study. Finally, we will give an overview of our methodology.

\section{Problematic elements}

\subsection{Shocks in our relationship with information}

2.1.1. The cognitive market. The "contemporary structuring of the 'cognitive market,' especially since the advent of the Internet phenomenon, does not always lead to the spread of knowledge" [1]. This market, Bronner [7] described it as a space where cognitive products are exchanged and are sometimes in a situation of competition, sometimes in a monopoly or quasi-monopoly condition. However, these various cognitive products may equally well be empirical data, mere hypotheses or, worse, irrational beliefs. Indeed, if the relationship with information has evolved, it is also because the extent of the information panorama has radically changed in a very short time, in quantity, in type of medium and sources.

In order to measure this "explosion," let us recall this article from the French daily newspaper Libération which reported the statement of the former head of the Google company, Eric Schmidt, who estimated, in 2010, that humanity produced the 
equivalent of five exabytes of information every two days, the equivalent of what was produced "between the beginning of human culture and 2003" [8]. And, a long way from being decreased, it is a safe bet that this growth will continue its exponential increase in the coming years.

At the same time, the types of media, as well as the media used to disseminate media, have extraordinarily diversified. Moreover, the supports have been "dematerialized," notably thanks to cloud computing.

2.1.2. Disintermediation. In addition, we can be concerned by the "disintermediation" phenomena [9], which is defined as the ability to bypass intermediaries (librarians, teachers, etc.) and to directly gain access to information [10]. This question is not specific to education, but nowadays, every student can access an impressive wealth of information without filters.

Nevertheless, gatekeepers did not disappear. Input of online peers is becoming central with social media. So, it may be suggested that this mediation process was partly transferred to contacts on social media. For example, according to the Pew Research Center, the US "online news consumers were about equally likely to get news by going directly to a news website $(36 \%$ of the times they got news, on average) as getting it through social media (35\%)", when asked how they arrived at news in their Web interaction [11].

\subsection{From Information Consumers to "Produsers"}

Finally, the production of information is no longer the privilege of a few. The rise of printing and other subsequent technologies, coupled with a massive expansion in access to school, contributed to the creation of information by anyone, and its publication as well as its dissemination. Again, information and communication technologies have propelled this phenomenon.

To this end, using "Web 2.0, end users have opportunities to create information, and consequently knowledge" [12], daily and instantly. A fortiori, information is no longer static and becomes the object of remobilizations and iterative transformations.

Thus, from one status (actor, author or interpret) to the other (spectator or reader), creation and consumption borders become more porous. In order to identify this phenomenon, the concept of "produser" is suggested. In fact, in Web 2.0 environments "the concept of produser, derived by merging producer and user, is adopted instead to convey the active engagement in 'the collaborative and continuous building and extending of existing content in pursuit of further improvement"

[13] [14].

\section{Research Question and Contributions to Knowledge}

\subsection{Research Question}

In other words, ICT have wrought profound changes in our dailies. Considering that, it seems to us that the traditional information literacy models, designed when borders were sharper, can no longer fully respond to contemporary realities. That is to say that established literacies frameworks are overwhelmed with information technology and Web 2.0. In that way, teachers are already confronted with changes in their students' practices: for example, three in four students already use Wikipedia more or less regularly in their academic work [15]. So, there are already operational approach in students' everyday life.

The purpose of this research is to get an accurate portrait of learners' practices to assess information on the social Web. More specifically, our research question is: What are the critical thinking strategies deployed by learners in their social Web activities?

A mixed and sequential design will allow us to answer two specific objectives. The first one, using a quantitative methodology, aims to evaluate any discrepancy between the perception (confidence and estimation) of competence that learners have in terms of their critical thinking and their effective competence.

The second objective, using a qualitative methodology, aims to better understand strategies used by learners to manipulate information on the social Web throughout pedagogical activity.

\subsection{Expected Contribution to the Advancement of Knowledge}

This research will sustain reflections about $21^{\text {st }}$ century digital and information literacy frameworks that are being developed by many governmental, academic or private institutions.

It will also allow us to empirically compare the learners critical thinking, as it is declared by students and as it can be measured in a traditional context, but also as it is observed in online pedagogical strategy. That will offer the opportunity to deduce distinctions related to the curricular profile of students and to lay the groundwork for pedagogical strategies that foster the development of the information literacy.

In addition, our reflection should also contribute to the emerging debate on the multiple facets of digital identity in the way that "digital interfaces change perception on oneself, the Other and the world" [16] and digital citizenship. 
Finally, in an interdisciplinary approach, we believe that this research will feed into the scientific reflection on social phenomena where young citizens relationship with information on the Web appears to be a key factor of radicalization.

\section{Conceptual Framework}

Our conceptual framework is based on the social cognitive learning theory. Consequently, as learning is social construct, it is also the product of interdependent personal, environmental and behavioural factors $[17,18]$. These three factors can be related to the three dimensions of our subject, namely the metaliteracy (4.1), connectivist pedagogy (4.2) and metacognition (Error! Reference source not found.).

\subsection{Information Literacy to Metaliteracy, An Evolving Concept Following Technological Evolution}

4.1.1. A traditional corner stone in media education. Paul Zurkowski [19] is usually credited with the concept "information literacy." While he presided at the Information industry association, he proposed a very utilitarian approach to the concept. According to him, "in our age of information overabundance, being information literate means being able to find what is known or knowable on any subject." In this context, Information Literacy was first established as a response to libraries' needs.

Actually, Information literacy has been an evolving concept for the last 40 years. In the following table (Table 1), we tried to summarize five of the main frameworks suggested over the years. It may be noted, however, that there are some similarities between them.

This utilitarian dimension that many authors challenges [20] [21] could be particularly explained by the fact that "Information literacy, in its central features, has always been influenced and determined by information environments," according to Špiranec [9].

It should also be emphasized that the concept of information literacy is not shared in "francophonie," thus favouring the one of "culture informationnelle" which could literally be translated as informational culture. By this, the French expression that Serres describes as a "broader set, and still not well-defined, of knowledge in different information fields" [20] aims to include implicit ideas related to our relationship to the media world and.

Even if the acronym of EMI (Éducation aux médias et à l'information for media and information education) can also be found in French high school libraries, core skills of information literacy are mobilized to the same end. In addition, in Québec, we can suggest many links between information literacy and the key underpinnings of the broad area of learning "Media awareness."

And that overview does not even include the many proposals of literacies that were formulated to respond to the emergence of new media, as visual literacy [22], media literacy [23], digital literacy [24], cyber literacy [25], etc. Therefore, if an effort was made to renew the scope of literacies, students' profiles and habits evolved more quickly considering shocks in our relationship with information.

Table 1. Summary of five of the main information literacy frameworks

\begin{tabular}{|c|c|c|c|c|c|}
\hline & Big6, 1988 & ALA, 1989 & Kuhlthau, 1993 & SCONUL, 1999 & ACRL, 2000 \\
\hline 1 & $\begin{array}{l}\text { Identify subject } \\
\text { Express a need }\end{array}$ & Express a need & Express a need & Express a need & Express a need \\
\hline 2 & $\begin{array}{l}\text { Identify strategy } \\
\text { Find }\end{array}$ & Identify subject & $\begin{array}{l}\text { Identify subject } \\
\text { Identify strategy }\end{array}$ & Identify subject & $\begin{array}{l}\text { Find, locate and } \\
\text { access }\end{array}$ \\
\hline 3 & Locate and access & $\begin{array}{l}\text { Find, locate and } \\
\text { Access } \\
\text { Evaluate }\end{array}$ & $\begin{array}{l}\text { Find, locate and } \\
\text { access }\end{array}$ & Identify strategy & Evaluate \\
\hline 4 & Use & Organize & Evaluate & $\begin{array}{l}\text { Find, locate and } \\
\text { access }\end{array}$ & Use \\
\hline 5 & Synthesize & Use & $\begin{array}{l}\text { Find, locate and } \\
\text { access }\end{array}$ & Evaluate & $\begin{array}{l}\text { Manipulate } \\
\text { ethically }\end{array}$ \\
\hline 6 & Evaluate & & $\begin{array}{l}\text { Organize } \\
\text { Use }\end{array}$ & Organize & \\
\hline 7 & & & & Synthesize & \\
\hline
\end{tabular}

4.1.2 "Reframing the Frameworks" for the New Technological Era. Taking these contemporary realities into account, several authors suggest revamped frameworks to push the limits such as diversity of platforms and to include Web realities enhancing collaborative work and sharing experience. Eventually, Mackey and Jacobson [26] 
suggested Metaliteracy as a new proposal, because "producing and sharing information are critical activities in participatory Web 2.0 environments." In this context, Metaliteracy should be considered as "an overarching, self-referential, and comprehensive framework" where evaluation of information is essential in networked digital environments.

Metaliteracy is defined as the "critical awareness of why we do what we do with information" [27]. It emphasizes the mastery of ICTs and the understanging of the social dimension of learning. In that way, metaliteracy could be considered as a personal factor conducive to learner's self-efficacy when accomplishing scholar tasks.

\subsection{Connectivism: Digital Strategies for Nowadays Environments}

4.2.1. New Challenges of New Online environments. According to Serres, "during the last few years, training learners to locate, identify, discern, evaluate the origin, the reliability, the quality and the relevance of information has become one of the most crucial challenges for school which is, unfortunately, not well equipped for this task" [20]. Reproducing the expression by Brabazon, Špiranec suggest that "the 'Google effect' [...] flattened expertise and saturated inexperienced students with low-grade information. [That is why] Brabazon pledges for re-intermediation" and we think that a part could be done by peers.

This challenge is significant, but the unexpected Web 2.0 effects, sometimes undesirable, demands that we make an effort and commitment to contain this situation. We suggest considering that cognitive process should become much faster and interconnected to reflect information acceleration.

Above all, we must bear in mind that the students' feeling of autonomy with ICT is not sufficient to reasonably manipulate information, particularly on the Web. The last "US election, with its steady stream of fake news, its easily debunked but widely circulating conspiracy theories" [28], is an invitation to work on more social literacies that accompanies social media.

4.2.2. Pedagogical Connectivism: A Starting Place Answering Digital Challenges. Many researches were conducted in traditional classrooms, particularly about critical thinking. For example, Watson-Glaser Critical Thinking Appraisal (WGCTA) [29], one of the most widely used tools, has been developed in 1925. It is therefore necessary to think of a renovated scholar environment to study critical thinking in our contemporary conditions.

Connectivism is a learning theory that emerged in the second half of the 2000s. It was developed by Siemens [3] and Downes [4], to integrate the notion of network connections and thus to overcome behaviourism, cognitivism or constructivism limits.

In practice, connectivism is characterized by a number of essential principles and, according to Dunaway, there are "similarities between [these] principles and emerging conceptualizations of information literacy" [12].

Consequently, comparing Metaliteracy and connectivism prescriptions, we suggest that bridges can easily be built between them. We found that these connections would particularly be relevant concerning diversity of sources and points of view question and, above all, information evaluation skills.

In practice, connectivist proposal will be an efficient framework to test students strategies on the social Web.

\subsection{Critical Thinking Strategies: "Thinking About Thinking" And Metacognition}

Finally, the social cognitive theory seems to be conducive to analyze the learners regulation strategies by insisting on their autonomy [30]. It therefore offers a relevant framework for the interpretation of regulation mechanisms. We can here suppose that the students' behaviour surfing on social Web media is strongly influenced by mechanisms of social regulation, but also by mechanisms of metacognition and self-regulation especially when it comes to evaluating information. Considering the triadic causal structure of Bandura's Social-Cognitive Theory [17], critical thinking can be considered as a consequence of cognitive strategies that are activated by learners for their own behaviour self-regulation strategies. In this context, critical thinking could be understood as one of the expressions of the learner's strategies [31].

More precisely, behavioural dimensions of social cognitive theory offers the possibility to understand mechanisms that allow the student to self-regulate, that is to say "to observe his mechanisms and his operations in relation to the situations encountered, to be able to readjust behaviours and knowledge about tasks and their own ways of doing things" [32].

Critical thinking strategies may be associated with metacognition [33], or in the process of "thinking about thinking," as proposed by Flavell [34]. Thus, the mobilized critical thinking strategies can be understood as the products of the different facets of metacognition [35-37] that are planning, control or regulation strategies [38].

\section{Methodology}

We propose, for this research proposal, a comparative case study between learners of "CEGEP" students (Québec, Canada) in humanities 
and social sciences and "lycée" students (France) in economics and social sciences. These two levels are just before the transition to University. The cases will be selected according to criteria allowing comparability of these, such as regional sociodemographic profiles and the size of institutions. This international comparison will aim to contrast behaviours which could be attributable to school curricula. As we would like to have a descriptive research, we believe that it would be better to mobilize not only quantitative methods [39], that is why this research uses mixed methods.

Quantitative data collection mobilizes the first two subscales of the Critical Thinking Toolkit proposed by Stupple et al. [40] measuring participants believe about their own critical thinking (Cronbach's alpha of the "Confidence in Critical Thinking" scale: $\alpha=0.92$; "Valuing Critical Thinking" scale: $\alpha=0.79$ ) and a recent version of WGCTA by Watson [29] to "measure" critical thinking around five dimensions. The validity of WCGTA scales has been estimated between $0.75<\alpha<0.8$ for United States [29] and between $0.77<\alpha<0.81$ for Great Britain [41]. In order to adequately translate these questionnaires from English into French, Vallerand's [42] transcultural validation process is mobilized. This translation will be tested during a validation study with a pre-test group of 10 students. Once that is accomplished, we will carry out an exploratory factor analysis [43] with the first group in order to calculate the coefficient of reliability. For this we will use the Cronbach alpha [44] which will determine the internal coherence and the mean correlation of the elements. Finally, the two questionnaires will be used with five to six classes $(n \cong 200)$ in the two institutions.

Qualitative data collection is based on a nonparticipatory observation of learners' digital activities. We will also have a small number of semidirected interviews with learners about their critical thinking strategies on the social Web, as proposed by Gagnon [45]. For data processing and coding, we are open to use a mixed coding [46] based on the Gagnon's framework [45], keeping the door open for emerging codes. We will follow the process suggested by Van der Maren [47], particularly with regard to counter-coding for which we will aim for an $80 \%$ inter-coders agreement.

These measures will be realized from fall 2018 to spring 2019. Quantitative data will be processed using SPSS software, while qualitative data will be examined under IRaMuTeQ and QDAMiner.

\section{Conclusion}

The rapid changes taking place in our world, especially about information dissemination, as well as the aspirations and habits of coming generations, are forcing the world of education to implement new practices into pedagogical strategies.

That is why we are going to develop a research which will contribute a snapshot of current usage of social media to manipulate information, especially during the evaluation phase. At the same time, it will be an occasion to test a connectivist scenario.

The study we are now producing will be an initial step to develop pedagogical tools for future research and studies that will be conducted in the context of participatory action research.

Obviously, this very brief research proposal is a summary and is certainly something that will be worth discussing in more detail. The reader is therefore invited to question our approach and to share his suggestions in order to improve it.

\section{References}

[1] Sauvajol-Rialland, C.: Infobésité. Vuibert, Paris, France (2013).

[2] Bronner, G.: La pensée extrême. Comment des hommes ordinaires deviennent des fanatiques. Denoël, Paris, France (2009).

[3] Siemens, G.: Connectivism: A learning theory for the digital age, http://www.elearnspace.org/Articles/ connectivism.htm.

[4] Downes, S.: Places to go: Connectivism and connective knowledge. Innov. J. Online Educ. 5, 6 (2008).

[5] American Library Association: Presidential Committee on Information Literacy: Final Report. American Library Association, Washington, DC (1989).

[6] Scriven, M., Paul, R.: Critical Thinking as Defined by the National Council for Excellence in Critical Thinking. Presented at the 8th Annual International Conference on Critical Thinking and Education Reform (1987).

[7] Bronner, G.: L'empire des croyances. Presses universitaires de France, Paris, France (2003).

[8]Siméon, G.: Données le vertige,http://www.liberation. fr/futurs/2012/12/03/donnees-le-vertige_864585, (2012).

[9] Špiranec, S.: Information literacy in Web 2.0 environments: emerging dimensions of research. Libellarium J. Hist. Writ. Books Mem. Inst. 7, 55-72 (2014).

[10]Eysenbach, G., From intermediation to disintermediation and apomediation: new models for consumers to access and assess the credibility of health information in the age of Web 2. 0. Stud. Health Technol. Inform. 129, 162-169 (2007).

[11] Mitchell, A., Gottfried, J., Shearer, E., Lu, K., How Americans Encounter, Recall and Act Upon Digital News, http://www.journalism.org/2017/02/09/how-americansencounter-recall-and-act-upon-digital-news/, (2017). 
[12] Dunaway, M.K.: Connectivism: Learning theory and pedagogical practice for networked information landscapes. Ref. Serv. Rev. 39, 675-685 (2011).

[13] Bruns, A.: Blogs, Wikipedia, Second life, and Beyond: from production to produsage. New York: Peter Lang, New York (2008).

[14] Andretta, S.: Web 2.0: from information literacy to transliteracy. In: Information Literacy beyond Library. pp. 53-64. Facet Publishing, Londres, Royaume-Uni (2012).

[15] Head, A.J., Eisenberg, M.B.: How today's college students use Wikipedia for course-related research. First Monday. 15, (2010)

[16] Georges, F.: Représentation de soi et identité numérique. Réseaux. 165-193 (2009).

[17] Bandura, A.: Social foundations of thought and action: a social cognitive theory. Prentice-Hall, Englewood Cliffs, N.J. (1986).

[18] Bandura, A.: Social cognitive theory: An agentic perspective. Annu. Rev. Psychol. 52, 1-26 (2001).

[19] Zurkowski, P.G.: The Information Service Environment Relationships and Priorities. Related Paper No. 5. (1974).

[20] Serres, A.: Questions autour de la culture informationnelle. Can. J. Inf. Libr. Sci. 31, 69-85 (2007).

[21] Simonnot, B.: Culture informationnelle, culture numérique: au-delà de l'utilitaire. In: Serres, A. (ed.) Penser la culture informationnelle. pp. 25-37. Hermes science publications : Lavoisier, Paris, France (2009).

[22] Debes, J.L.: The Loom of Visual Literacy--An Overview. Audiov. Instr. (1969)

[23] Jones, B., Flannigan, S.L.: Connecting the digital dots: Literacy of the 21st century. Educ. Q. 29, 8-10 (2006).

[24] Gilster, P.: Digital literacy. Wiley Computer Pub. New York (1997).

[25] Stiller, E., LeBlanc, C.: From computer literacy to cyber-literacy. J. Comput. Sci. Coll. 21, 4-13 (2006).

[26] Mackey, T.P., Jacobson, T.E.: Reframing Information Literacy as a Metaliteracy. Coll. Res. Libr. 72, 62-78 (2011).

[27] Witek, D., Grettano, T.: Teaching metaliteracy: a new paradigm in action. Ref. Serv. Rev. 42, 188-208 (2014).

[28] Sismondo, S.: Post-truth? Soc. Stud. Sci. 47, 3-6 (2017)

[29] Watson, G.: Watson-Glaser critical thinking appraisal. Psychological Corporation, San Antonio, TX (1980).
[30] Pintrich, P.R., de Groot, E.V.: Motivational and selfregulated learning components of classroom academic performance. J. Educ. Psychol. 82, 33-40 (1990).

[31] Lipman, M.: Critical Thinking: What Can It Be? Educ. Leadersh. 46, 38-43 (1988).

[32] Bégin, C.: Enseigner des stratégies d'apprentissage à l'université application d'un modèle et analyse des changements consécutifs à leur enseignement, http://savoirs.usherbrooke.ca/handle/11143/897, (2003).

[33] Tempelaar, D.T.: The role of metacognition in business education. Ind. High. Educ. 20, 291-297 (2006).

[34] Flavell, J.H.: Metacognition and cognitive monitoring: A new area of cognitive-developmental inquiry. Am. Psychol. 34, 906 (1979).

[35] Kuhn, D.: A Developmental Model of Critical Thinking. Educ. Res. 28, 16-46 (1999).

[36] Dean, D., Kuhn, D.: Metacognition and Critical Thinking. (2003).

[37] Magno, C.: The role of metacognitive skills in developing critical thinking. Metacognition Learn. 5, 137$156(2010)$

[38] Boulet, A., Chevrier, J., Savoie-Zajc, L.: Les stratégies d'apprentissage à l'université. Presses de l’Université du Québec, Sainte-Foy, Québec (1996).

[39] Ellis, A.K., Fouts, J.T.: Research on educational innovations. Eye on Education, Princeton Junction, NewJersey (1993).

[40] Stupple, E.J.N., Maratos, F.A., Elander, J., Hunt, T.E., Cheung, K.Y.F., Aubeeluck, A.V.: Development of the Critical Thinking Toolkit (CriTT): A measure of student attitudes and beliefs about critical thinking. Think. Ski. Creat. 23, 91-100 (2017).

[41] Rust, J.: Watson Glaser Critical Thinking Appraisal UK Edition-Manual . London: The Pschychological Corporation. The Pschychological Corporation, Londres, Royaume-Uni (2002).

[42] Vallerand, R.J.: Vers une méthodologie de validation transculturelle de questionnaires psychologiques: Implications pour la recherche en langue française. Can. Psychol. 30, (1989).

[43] Kim, J.-O.: Factor analysis statistical methods and practical issues. SAGE, Londres, Royaume-Uni (1978).

[44] Cronbach, L.J.: Coefficient alpha and the internal structure of tests. psychometrika. 16, 297-334 (1951).

[45] Gagnon, M.: Proposition d'une grille d'analyse des pratiques critiques d'élèves en situation de résolution de problèmes dits complexes. Rev. Rech. Qual. 30, 122-147 (2011).

[46] Miles, M.B., Huberman, A.M.: Analyse des données qualitatives. De Boeck Supérieur (2003). 
International Journal of Digital Society (IJDS), Volume 8, Issue 2, June 2017

[47] Van der Maren, J.-M.: Méthodes de recherche pour l'éducation. Presses de l'Université de Montréal et De Boeck Supérieur, Montréal, Québec/Bruxelles, Belgique (1996). 